\title{
DOS DIREITOS HUMANOS AOS DIREITOS FUNDAMENTAIS: A FORMAÇÃO DO DIREITO MODERNO NAANTIGUIDADE E NO MEDIEVO
}

\section{Eneas Romero de Vasconcelos}

Mestre em Direito e Estado pela Universidade de Brasília. Professor de Filosofia do Direito e de Direito da Criança e do Adolescente. Promotor de Justiça. eneasromero@hotmail.com

Sumário: Introdução. 1) Desenvolvimento dos direitos humanos no Ocidente. 2) Há direitos humanos no mundo antigo e medieval? Conclusão.

Resumo: Os direitos humanos fazem parte hoje do cotidiano das democracias contemporâneas, mas eles têm uma história muito mais longa. A compreensão da história dos direitos humanos é muito importante para que se compreenda o seu significado para o Estado e para a sociedade moderna. O estudo das origens medievais dos direitos humanos costuma ser negligenciado, mas o significado atual dos direitos humanos na sociedade moderna apenas adquiriu sua importância baseadas na filosofia grega, no direito romano e no Cristianismo que tornaram possível a construção da teoria e da prática dos direitos humanos na sociedade moderna até hoje.

Palavras-chave: História do direito. Direitos humanos. Antiguidade e medievo.

\section{INTRODUÇÃO: A ATUALIDADE DA HISTÓRIA DOS DIREITOS HUMANOS}

Os direitos humanos estão em todos os lugares. O cidadão preso pede liberdade provisória afirmando que o Direito impede, salvo em casos excepcionais, a prisão cautelar durante a instrução processual; o motorista, ao ser parado por agente estatal para realizar um teste de bafômetro para verificar o índice de álcool em seu corpo, considera que pode se negar a fazer o exame, eventualmente até mesmo sem sanções jurídicas, pois a Constituição garante que ninguém será forçado a prestar provas contra si mesmo; a tortura contra um cidadão suspeito é inadmissível; imposto novo só se for criado por lei anterior; "não há crime sem 
lei anterior que o defina, nem pena sem prévia cominação legal e ninguém será obrigado a fazer ou deixar de fazer alguma coisa senão em virtude de lei." São as promessas feitas pelo art. $5^{\circ}$ I, II, XXXIX, LVII e LXIII e art. 150, I e III, b da Constituição Federal, que esperamos sejam cumpridas.

Hoje, todo mundo pensa que tem direitos que estão acima da lei e tem mesmo: são os direitos fundamentais do cidadão, protegidos pela Constituição, mas, nem sempre, foi assim e, na verdade, muitos destes direitos são bem recentes. A tortura como técnica de interrogatório e obtenção de confissão era corriqueira nos processos penais; a liberdade religiosa, por séculos, não passava de uma miragem; as mulheres, até recentemente, não votavam, nem poderiam ser eleitas; o homossexualismo era crime; os filhos gerados fora do casamento não tinham direitos e um negro, só mesmo em sonho, poderia querer ser Presidente da República.

No Estado Democrático de Direito, a igualdade entre as raças e os gêneros, entre os filhos legítimos e 'ilegítimos', a liberdade religiosa e a vedação incondicional à tortura são direitos humanos reconhecidos e protegidos; hoje, todo cidadão sabe que, se for preso, não poderá ser torturado; toda mulher sabe que, se ficar grávida, seu filho terá direito a alimentos a serem prestados pelo genitor, pouco importando se o pai for solteiro, viúvo ou casado.

Os direitos humanos fazem parte do nosso quotidiano e são tão importantes que sem direitos humanos não há sequer paz, como expressa BOBBIO, em feliz síntese: "Direitos do homem, democracia e paz são três momentos necessários do mesmo movimento histórico: sem direitos do homem reconhecidos e protegidos, não há democracia; sem democracia, não existem as condições mínimas para a solução pacífica dos conflitos." (1992, p.1).

Na guerra, acontecimentos trágicos, como a morte e a fome, fazem parte do próprio jogo pelo poder, a ser conquistado através da força, e o século XX foi pródigo em demonstrações dos desastres humanitários que acompanharam as guerras, conforme demonstra JUDT (2008, p. 31-32).

As guerras do século XXI, externas ou internas, com os milhares de mortos do Iraque e do Sudão, ou da Geórgia, não nos deixam esquecer a incompatibilidade entre as guerras e os direitos humanos, mas uma sociedade que não respeita, sistematicamente, os direitos humanos, como no Sudão ou no Zimbábue hoje, os conflitos acabam encontrando solução através do uso da força, da violência e, em última análise, resultam na guerra civil.

Mas se a paz é necessária para um respeito mínimo aos direitos humanos, o respeito aos direitos do homem é igualmente importante em tempos de paz; até mesmo os países mais ricos e desenvolvidos enfrentam graves problemas para garantir o respeito aos direitos do homem, como demonstra o problema da imigração (e dos direitos dos imigrantes na Comunidade Européia e nos EUA), da tolerância religiosa, da eutanásia e da liberdade de expressão. 
Os direitos do homem impõem, portanto, obrigações para países ricos e para países pobres, desenvolvidos e subdesenvolvidos, em tempos de guerra (conforme previsto pela Convenção de Genebra) ou de paz; e devem ser respeitados até mesmo por países não democráticos signatários da Declaração Universal de Direitos do Homem e demais Tratados Internacionais de Direitos Humanos, conforme leciona CANÇADO TRINDADE (2002, p. 649-650):

[...] ao ratificarem os tratados de direitos humanos os Estados Partes contraem, a par das obrigações convencionais atinentes a cada um dos direitos protegidos, também obrigações gerais da maior importância, consignadas daqueles tratados. Uma delas é a de respeitar e assegurar o respeito dos direitos protegidos - o que requer medidas positivas por parte dos Estado - e outra é de adequar o ordenamento jurídico interno à normativa internacional de proteção. Esta última requer que se adote a legislação necessária para dar efetividade às normas convencionais de proteção, suprindo eventuais lacunas no direito interno, ou então que se alterem disposições legais nacionais com o propósito de harmonizá-las com as normas convencionais de proteção - tal como requerido pelos tratados de direitos humanos.

Se, por um lado, há amplo consenso sobre muitos dos direitos humanos que se deve preservar, levando BOBBIO a afirmar que "o problema fundamental em relação aos direitos do homem, hoje, não é tanto de justificá-los, mas o de protegê-los" (1992, p. 24), ainda há um amplo dissenso em relação a parte dos direitos humanos que geram acaloradas controvérsias e estão longe de encontrar um consenso: o aborto e a eutanásia, por exemplo, demonstram claramente esta divergência. Afinal, uma pessoa, acometida de doença grave, incurável e dolorosa, tem o Direito a finalizar com a própria vida com auxílio médico para tornar o processo indolor? Uma mulher, grávida de um feto com grave deformidade física incapacitante, anencefalia, por exemplo, tem o direito a abortar o feto nos primeiros meses de gestação?

Em ambos os casos, o que se decidirá é se, no sistema de princípios, o direito à liberdade compreende a liberdade de antecipar o fim da própria vida de modo indolor e se o direito à liberdade da mulher abrange a possibilidade de interromper a gravidez de um feto com grave deformidade física incapacitante. Embora o direito à liberdade, um dos direitos humanos 'clássicos', seja um dos direitos controvertidos neste caso, a resposta para a questão é mais complexa e implica em uma abrangente reconstrução do significado da liberdade, da dignidade e dos próprios direitos fundamentais nos sistemas jurídicos democráticos.

Esta reconstrução, aparentemente clarividente, implica na necessidade de se compreender como os direitos humanos se constituíram ao longo da história e quais as leituras e releituras possíveis para cada direito hoje: o que retorna na discussão é o que sempre esteve em questão, a construção do significado da igualdade, da liberdade e da dignidade da pessoa humana, mas o significado atual 
da igualdade e da liberdade é tão diferente do significado passado que corremos, sempre, o risco de equiparar situações diferentes, recaindo no paradoxo da faca de Lichtenberg: "mudou o cabo e botou uma lâmina nova, e porque gravou nela o mesmo nome espera que seja considerada como instrumento original."

Por isso, a interpretação dos direitos humanos hoje implica na necessidade de reconstrução do constitucionalismo, como demonstram JACKON \& TUSHNET (2006, p. 243), que resultou na construção da própria idéia de direitos humanos, conceito submetido à permanente transformação e à graves desafios, que colocam em risco os próprios direitos humanos, como bem demonstrou a polarização ideológica do início do século XX e as Guerras Mundiais com os resultados desastrosos e trágicos conhecidos: a história, do mundo antigo ao contemporâneo, ensina que a civilização é uma conquista, que para ser mantida precisa ser permanente cultivada para que seja preservada, como demonstra NEMO (2002, p. 3).

Não podemos esquecer, portanto, que os direitos humanos foram resultado de um consenso lentamente conquistado durante a história a custa de muito sangue e sofrimento em uma luta sem fim que continua, mesmo no Estado de Direito, em permanente renovação e reconstrução: precisamos sempre relembrar os limites até onde o Estado pode ir e re-definir os direitos humanos.

O terrorismo internacional, notadamente depois do atentado de 11 de setembro, propõe novos desafios aos direitos humanos, que devem ser respeitados em um momento de tensão entre Estado e cidadão: Estado que, no mundo contemporâneo, precisa ser cada dia mais poderoso (para combater o terrorismo e evitar tragédias humanitárias, distribuir recursos sociais e garantir segurança pública) para respeitar os direitos do cidadão, sempre com o risco de, em razão do poder excessivo, tornar-se o agente maior da opressão.

A questão central do Estado Democrático de Direito é, portanto, saber como conciliar o ideal de Justiça, representado por Têmis, e o poder expansivo do Estado, representado por Leviatã. A expressão é de MARCELO NEVES:

O problema do Estado Democrático de Direito é exatamente o de como conciliar poder eficiente como direito legitimador. Na tradição ocidental, Leviatã apresenta-se como símbolo do poder expansivo do Estado. Têmis, antes de tudo, representa a justiça abstrata. O Estado Democrático de Direito caracteriza-se precisamente por ser uma tentativa de construir uma relação sólida e fecunda entre Têmis e Leviatã - portanto, de superar a contradição tradicional entre justiça divina e poder terreno (um paradoxo); uma tentativa no sentido de que a justiça deveria perder sua dimensão transcendente e o poder não mais ser considerado mera facticidade: o Estado Democrático de Direito como invenção da modernidade. Nesse tipo de Estado, Têmis deixa de ser um símbolo abstrato de justiça para se tornar uma referência real e concreta de orientação da atividade de Leviatã. Este, por sua vez, é rearticulado para superar a sua tendência expansiva, incompatível coma complexidade sistêmica e a pluralidade de interesses, valores e discursos da sociedade moderna. Não se trata apenas de uma fórmula para 
'domesticar' ou 'domar' o Leviatã. Antes, o problema consiste em estabelecer, apesar das tensões e conflitos, uma relação construtiva entre Têmis e Leviatã, de tal maneira que o direito não se mantenha como uma mera abstração e o poder político não se torne impotente por sua hipertrófica ou falta de referência legitimadora (2006, p. XVIII e XIX).

No constitucionalismo, o Estado passa a existir para garantir os direitos do homem, mas corre o risco de ser o principal agente de desrespeito aos direitos que deveria ter como função preservar.

O que, no Estado Democrático de Direito, deve ser preservado por estar de acordo com os direitos humanos e o que deve rejeitado por incompatível? O Estado pode, para combater a criminalidade ou o terrorismo, prender um cidadão sem acusação formal, ou com uma acusação precária, para evitar um mal maior e garantir a liberdade de outros cidadãos?

Reconstruir o longo trajeto (desde o mundo Antigo e Medieval até Contemporâneo, com ênfase nas Revoluções da época Moderna que resultaram no surgimento das primeiras declarações de direito e na universalização dos direitos humanos internacionais e na proteção dos direitos fundamentais das Constituições dos Estados Nacionais) é o caminho mais apropriado para se responder a qualquer pergunta sobre o significado dos direitos humanos e fundamentais no Estado Democrático de Direito e "o que se conta, nestas páginas, é a parte mais bela e importante de toda História: a revelação de que todos os seres humanos, apesar das inúmeras diferenças biológicas e culturais que os distinguem entre si, merecem igual respeito, como únicos entes no mundo capazes de amar, descobrir a verdade e criar a beleza. É o reconhecimento universal de que, em razão dessa radical igualdade, ninguém - nenhum indivíduo, gênero, etnia, classe social, grupo religioso ou nação - pode afirmar-se superior aos demais", de acordo com a lição de COMPARATO (2004, p. 1). Mas quando, afinal, passamos a ser considerados iguais e livres?

\section{Desenvolvimento dos direitos humanos no OCIDENTE}

Quando surgem os direitos humanos? Na democracia grega? No direito romano? Nos ensinamentos do Rei Salomão? Com o surgimento de Cristo?

A primeira questão que se coloca ao se analisar o desenvolvimento histórico dos direitos humanos é estabelecer até quando devemos retroceder na história, o que implica identificar em que momento passou-se a reconhecer os direitos humanos, garantindo-se a cada indivíduo a reivindicação de tratamento igualitário: a partir de quando toda pessoa passou a ser tratada com igual respeito e consideração? Havia direitos humanos nas sociedades sem Estado ou nas Monarquias Sagradas do Oriente Próximo? E, em Jerusalém, Roma e Atenas, nas capitais espirituais do Ocidente, havia direitos humanos? Ou os direitos humanos apareceram, então, 
na Idade Média? Ou somente na Idade Moderna? Os direitos humanos são, então, os filhos da Revolução Francesa?

Identificar o momento em que passamos a ter direitos humanos protegidos e reconhecidos é um problema muito mais complexo do que imagina nossa filosofia: em primeiro lugar porque a identificação do 'DNA' dos direitos humanos não pode ser encontrado em apenas um momento, em uma época, mas provêm de uma longa tradição histórica; em segundo lugar, porquanto os direitos humanos se constituem a partir da sucessiva adoção de diferentes idéias de diversos períodos históricos, que, lidas e relidas, passam a garantir a todo ser humano a reivindicação de igualdade, liberdade e dignidade; em terceiro lugar, porque qualquer estudo histórico é antes de tudo um estudo marcado pelas escolhas do autor do estudo, pois "como disse Friederich Nietzsche, nada que tenha história pode definir-se. Não obstante, um autor que não escreva obras de ficção tem o dever de revelar desde o começo alguns de seus prejuízos.”, segundo BERMAN (1996, p. 12): gostemos, ou não, os nosso preconceitos são determinantes para estabelecer quando os direitos humanos surgiram, pois "os preconceitos de um indivíduo são, muito mais do que seus juízos, a realidade histórica de seu ser.", conforme leciona GADAMER (2002, p. 416).

É só no Ocidente que há direitos humanos? Por acaso, não haveria direitos humanos na milenar China, Índia, Japão ou Irã? A resposta é: não. Os direitos humanos são filhos tardios da tradição jurídica ocidental e somente neste contexto podem ser conhecidos, pois foi na tradição jurídica do Ocidente (e de suas revoluções papal, luterana, gloriosa, americana, francesa e russa) que os direitos humanos surgiram e se desenvolveram, segundo BERMAN (1996, p. 3-29).

Portanto, quando começamos a contar a história dos direitos humanos, precisamos lembrar, com GADAMER, que "não é a história que pertence a nós mas nós é que a ela pertencemos" (2002, p. 415), pois, antes mesmo de nascermos, a história dos direitos humanos já havia sido contada aos nossos antepassados e nossa formação se dá a partir destas noções pressupostas que se transmitem pela própria linguagem que nós é legada (2002, p. 176): a escravidão, desde a infância, é ensinada como má por tratar de modo desigual as pessoas; as mulheres não são mais criadas para serem donas de casa, mas apenas para, eventualmente, escolherem dedicar suas vidas aos filhos e à família.

Nos séculos XIX e XX, a escravidão tornou-se universalmente ilícita por contrariar a dignidade da pessoa humana; a liberdade da mulher, porém, ainda encontra graves mitigações no mundo atual: no Irã, no Paquistão ou na Arábia Saudita a mulher não tem, nem de longe, a mesma liberdade da mulher ocidental e, mesmo no outro lado do mundo, elas continuam sendo as vítimas 'privilegiadas' da violência masculina, o que justificou, no Brasil, a criação de uma lei específica para enfrentar o problema. 
Historicamente, contudo, o tratamento desigual entre as pessoas com base na raça ou no gênero era 'normal'. Muitas das idéias que hoje parecem tão consensuais são tão recentes que nós esquecemos quão difíceis, sofridas, sangrentas, foram as lutas para se chegar a noção de que toda pessoa humana é igual em dignidade e deve ser tratada com igual respeito e consideração. Muitos erros, recentes inclusive, ocorreram durante esta história e ainda há hoje locais em que a intrínseca igualdade entre as pessoas ainda não é aceita: os direitos humanos, posto que universais, são filhos tardios do Ocidente e sua positivação é uma aquisição evolutiva da sociedade moderna

Estudar a construção desta tradição é indispensável para decidirmos o que faremos, a partir de agora, com os direitos humanos que herdamos? Qual o significado da dignidade hoje e quais as leituras possíveis para o amanhã? Os terroristas, ou os criminosos violentos, são, em razão da crueldade de seus atos, menos dignos do que os outros seres humanos?

Construir o significado atual e os desdobramentos futuros dos direitos humanos é a tarefa de cada geração e, de acordo com WARAT, “É impossível desconhecer que só se pode ler a história do direito como a história dos direitos humanos." (1997, p. 17). Tarefa que deve ser feita com a consciência de nossos prejuízos e pré-conceitos, no sentido empregado por GADAMER (2002, p. 415-416), para que possamos re-contar, do melhor modo, a história dos direitos humanos para resolver hoje, pensando no amanhã, quais direitos devem ser preservador e qual o significado de cada direito fundamental.

Esta questão, sempre atual, para ser compreendida adequadamente deve ser situada na reconstrução da tradição jurídica ocidental: a igualdade, a liberdade e a dignidade de cada indivíduo pertencem à tradição jurídica do Ocidente e somente a sua reconstrução, como reconhece BERMAN conduzirá a uma compreensão adequada do significado dos direitos humanos hoje, pois "Como expôs Goethe, a tradição não se herda: tem-se que conquistá-la.” (1996, p. 16).

Portanto, para manter viva a tradição dos direitos humanos, é preciso reconquistá-la, mas só se pode conquistar algo que conhecemos. É necessário, então, que conheçamos um pouco melhor a tradição que tornou possível, como afirma COMPARATO, "o reconhecimento universal de que [....] nenhum indivíduo, gênero, etnia classe social grupo religioso ou nação - pode afirmar-se superior aos demais.” (1004, p. 1).

A história dos direitos humanos conta como cada pessoa individualmente passou a ser reconhecida pelo direito como igual em dignidade e, em razão desta igualdade, cada homem passou a ter o direito de decidir autonomamente e livremente o melhor destino para si mesmo: o nascimento deixa de ser o fator determinante para o nosso destino. 


\section{HÁ DIREITOS HUMANOS NO MUNDO ANTIGO E MEDIEVAL?}

$\mathrm{Na}$ história do homem, as pessoas eram, inicialmente, reconhecidas como intrinsecamente diferentes: os Faraós, por exemplo, eram divindades na terra, superiores, por natureza, aos outros homens, como afirma NEMO (2002, p. 13); na república romana a sociedade era cindida entre cidadãos romanos do sexo masculino que falavam latim e os outros, segundo GORDON (2002, p. 30); o Papa, no final da idade média, era o representante de Deus na Terra, sendo, portanto, superior, aos homens comuns; o poder, nas Monarquias, era transmitido pela hereditariedade, sendo o nascimento o fator determinante para estabelecer o papel político da pessoa na sociedade e no Estado.

Neste contexto, não se pode falar em direitos inerentes ao homem enquanto homem, pois os homens eram tratados como naturalmente desiguais e dignos de tratamento diferente de acordo com o seu papel na sociedade. Com efeito, nas sociedades sem Estado ou nas Monarquias Sagradas do Oriente Próximo não havia direitos humanos porque as pessoas eram tratadas como naturalmente diferentes. Portanto, nem sempre houve direitos humanos, e é necessário identificar a partir de que momento os homens passaram a ser considerados como iguais e livres.

Frequentemente, Israel, Grécia e Roma são citadas, por NEMO, como as grandes precursoras do direito moderno construídos sob a égide da democracia grega, do direito romano e da teologia cristã (2002, p. 1-23): a partir da igualdade e da liberdade dos cidadãos da democracia atenienses e da igualdade dos filhos do Deus Pai, mediadas pelo direito romano, é que se construiu a noção moderna de igualdade dos direitos humanos.

Gregos, porém, segundo FERRY (2007, P. 78-79), não eram tão livres ou iguais quanto costumamos pensar: Sócrates foi condenado ao suicídio pela Justiça por introduzir novos deuses e corromper a juventude e Aristóteles e terminou a vida como exilado, fugindo de Atenas para evitar que a cidade pecasse pela terceira vez contra a filosofia, como ensina MARÍAS (2006, p. 66). Cristãos tampouco eram iguais apesar de igualmente filhos de Deus: no mundo medieval, nobres e camponeses, mesmo sendo todos filhos de Deus, recebiam um tratamento completamente diferente desde o nascimento; servos e camponeses estavam determinados a permanecer na condição social em que nasceram.

Em que sentido, então, uma democracia excludente que retirava o direito ao voto das minorias (mulheres, escravos e estrangeiros) que constituíam a maioria da população pode ser considerada responsável pela criação da noção de igualdade e liberdade entre os homens? Por que uma sociedade composta de servos e Reis pode ser considerada precursora no tratamento igualitário entre os homens, os filhos de Deus?

$\mathrm{Na}$ verdade, no sentido atribuído atualmente à igualdade e à liberdade as pessoas em Atenas, Roma ou em Jerusalém não poderiam ser consideradas como 
iguais ou livres, pois elas não tinham a liberdade de decidir plenamente sobre os seus destinos e eram tratadas de modo diferente de acordo com o papel social que ocupavam, mas isso não torna menos relevante a radical contribuição destas civilizações para a construção do sentido hodierno dos direitos humanos. A própria crítica à desigualdade (e. g. das mulheres, dos escravos) entre as pessoas naquela época já se trata de anacronismo: não podemos julgar uma sociedade antiga com os valores atuais; a escravidão, por exemplo, que sofreu duras e justas críticas na modernidade, era o modo de produção de toda economia antiga: sem ela a economia não funcionaria, o que explica, sem justificar, que ela fosse tratada, pelos pensadores da época, como natural.

Neste contexto, Aristóteles defendia que os homens livres devem dominar os escravos, inclusive para o próprio bem destes, pois Aristóteles reconhece a existência de escravos por natureza, afirmando que "pertence também ao desígnio da natureza que comande quem pode, por sua inteligência, tudo prover e, pelo contrário, que obedeça quem não possa contribuir para a prosperidade comum a não ser pelo trabalho de seu corpo. Esta partilha é salutar para o senhor e para o escravo." (1998, p. 2).

A história do homem, e dos seus direitos, não pode ser compreendida como seqüência permanente de conquistas que resultaram na sucessiva ampliação do respeito ao outro. Antes, ela se enreda em uma complexa teia em que grandes conquistas da civilização são desafiadas por rupturas que colocam em risco todas as lições lentamente adquiridas.

Atenas pereceu; Roma não resistiu às invasões bárbaras e Israel continua sendo um território de instabilidade e incerteza. A filosofia grega, embora abalada, sobreviveu ao colapso da Grécia e permaneceu viva no Império Romano e no Medievo; o direito romano, concorrendo com o direito bárbaro, influenciou o direito medieval e foi determinante para a construção do direito moderno; a religião cristã, proscrita do Império Romano, acabou por conquistá-lo e sobreviveu a ele para servir como base religiosa para os tempos difíceis do inicio da Idade Média e como fundamento do poder político da Igreja na segunda metade da Idade Média.

A filosofia grega, o direito romano e a religião cristã foram severamente desafiados pela crise das civilizações que os criaram, mas, nos tempos difíceis da queda e no processo de aprendizado para a (re)conquista da civilização, transformaram-se na base do pensamento que tornou possível o surgimento do Estado Moderno e dos direitos humanos.

O colapso dos impérios não representou a extinção das idéias construídas pelas civilizações e, na medida em que a estabilidade retornou, as idéias, mantidas de modo mais ou menos precário depois da derrocada, serviram de base para a construção de uma civilização que procurou nas idéias do passado a base para a re-elaboração de um novo sentido para a vida, como informa WIEACKER: 
A assimilação civilizacional significa simultaneamente uma educação espiritual que desperta uma nova força criadora; à educação externa acaba por se seguir um renascimento da pré-cultura a partir do novo sentido da vida, ao qual desde logo faziam falta a experiência anímica e espiritual para exprimir a própria existência com os meios da pré-cultura. Entre a adoção dos antigos valores civilizados e o posterior renascimento decorre, na maior parte dos casos, um longo trabalhoso processo de maturação, com uma grande insegurança dos próprios meios de expressão. Isto aplica-se, também, para a cultura da alta Idade Média [....] A filosofia européia encontra-se mais cedo com Boécio, com Dionísio de Areopagita, com Isidoro de Sevilha do que com Aristóteles, com Platão, e finalmente, com os pré-socráticos; as artes plásticas, primeiro com as formas da antiguidade tardia e bizantinas, depois com as helenístico-romanas, só mais tarde com as greco-clássicas e, por fim, com os seus precursores arcaicos.

Esta matriz fundamental domina também o ritmo da evolução jurídica européia, que constitui uma progressiva apropriação do patrimônio romanístico em desenvolvimento até aos nosso dias. Primeiramente, foram recebidos os elementos matérias e técnicos do direito vulgar. A transição para o séc. XII assiste ao encontro, sempre aberto e provisório, com a grande jurisprudência romana na versão do classicismo justinianeu, encontro acompanhado pela recepção da teoria jurídica e política de Aristóteles que produziu, na Suma de S. Tomás, o primeiro sistema europeu de direito natural. Só com o humanismo se iniciam as tentativas de arrancar ao Corpus Iuris justinianeu o autêntico direito romano clássico, tentativas que, mais tarde, a Escola Histórica de novo retomou e que a moderna romanística concluiu de forma metódica. (2004, p. 23-24).

O direito moderno, e os direitos humanos, são filhos tardios deste feliz encontro da teologia cristã, da filosofia grega e do direito romano, que se transforma para servir à formação do direito comum medieval a partir do qual se constrói o direito moderno:

Os primórdios dos ordenamentos jurídicos europeus encontram-se nas formas básicas de vida das sociedades romano-germânicas da alta Idade Média e nos três grandes poderes ordenadores que a antiguidade tardia tinha deixado: os restos da organização do império romano do ocidente, a igreja romana e a tradição escolar da antiguidade tardia, restos que os novos povos e tribos assentes no antigo corpo do império e no centro da Europa e de que se acabaram por apropriar. Cada um destes elementos trouxe à cultura jurídica européia e, assim, também a história do direito privado, contributos que a influenciaram ao longo dos tempos. Depois de longa maturação e muitos retrocessos, foi deste processo de apropriação que resultou A ciência jurídica da alta Idade Média. (2004, p. 15-16).

$\mathrm{Na}$ Idade Média encontram-se o direito romano, com a universalização do direito e o aumento da complexidade na solução de conflitos, a filosofia grega, com sua filosofia racionalista e complexa, e a religião cristã, com a reivindicação de uma nova noção de igualdade, de liberdade e de dignidade da pessoa humana, para formar o direito comum medieval que se funda na filosofia cristã, o que só é 
possível em decorrência das idéias herdadas pela Grécia Antiga, pelo Cristianismo de Israel e pelo Direito do Império Romano, que foram apropriadas e re-construídas na Europa Medieval e Moderna, tornado-se a base para o pensamento ocidental moderno e contemporâneo.

Para se compreender como se constitui a civilização, mais do que uma remissão às origens do ocidente, é necessário fazer-se uma breve reconstrução das idéias que fazem da Grécia, de Roma e de Israel, apesar do seu desmoronamento, tão especiais para a formação do ocidente.

Mas na própria sociedade grega já existia uma idéia totalmente nova: as pessoas, apesar das graves diferenças no tratamento jurídico e político, passaram a ser reconhecidas como iguais na medida em que detentoras de razão e submetidas a uma mesma lei (nomos), o que permitiu que, já naquela época, começasse a haver divergências sobre o significado da igualdade, levando Platão, na República, a reivindicar uma sociedade de filósofos em que todos teriam iguais oportunidades para que os mais talentosos pudessem alcançar a condição de filósofo e pudessem decidir as coisas do Estado.

Já na religião judaica, na tradição do Velho Testamento, o homem é elevado ao patamar de filho de Deus, feito à Sua imagem e semelhança. Na filosofia cristã, a reivindicação de igualdade se torna muito mais abrangente, pois o próprio Deus é representado passa a existir na pessoa de um homem, JESUS CRISTO: Deus é um homem e cada homem é feito à imagem e semelhança de Deus e pode alcançar o Reino dos Céus, independente de sua origem ou classe social, a salvação se dá pela fé.

No Cristianismo, os homens passam a ser considerados iguais, já que todos igualmente filhos do Deus, que se apresentou ao mundo na pessoa de Jesus Cristo, e o bom exercício do livre arbítrio é quem vai determinar se a pessoa vai obter a salvação: a pobreza, a riqueza ou a nobreza tornam-se secundárias diante de Deus, segundo FERRY (200, p. 92-93).

No mundo das idéias, o cristianismo rompe com a desigualdade natural das sociedades antigas e o reconhecimento da igualdade dos filhos de Deus, na história do pensamento, um caminho sem volta a partir do qual se erguerão os direitos humanos e o Direito e o Estado Moderno.

Embora desde Santo Agostinho a Filosofia tenha sido colocado a filosofia à serviço da religião cristã, na busca por conferir a profundidade teórica da filosofia para a religião cristã, a contribuição da religião sobre a Igualdade dos filhos de Deus será a base para a posterior democratização do conhecimento e dos projetos de vida.

Já em Santo Agostinho encontra-se justificada uma mudança na situação entre os filhos de Deus que somente podem ser salvos através da fé em Deus Cristo: a salvação é acessível a todos, ricos ou pobres, os mais humildes são os mais dignos de salvação (2007, p. 60). Neste contexto, o Direito Temporal, o direito que existe na Cidade dos Homens, no mundo dos ímpios, vai procurar no Direito Eterno o fundamento para a elaboração de um direito mais justo através 
do Direito Natural, cognoscível pelo através da inscrição da vontade divina em nossos corações, estampada em nossa alma a partir da vontade de Deus como um carimbo que reproduz no papel uma imagem moldada a partir de um modelo.

A fé se torna o único caminho para a salvação e o homem deve procurar, no seu íntimo, livrar-se do pecado para encontrar salvação na vida eterna e consolo na vida humana, nos difíceis tempos que acompanharam a queda do Império Romano.

A Igreja Cristã, concorrendo com religiões rivais, consolida-se ao longo da alta Idade Média, como a religião que dará conforto aos homens nos tempos difíceis. Com o desenvolvimento político, social e econômico ao longo da Idade Média a Igreja consegue adquirir papel de Proeminência e nos Séculos XI e XII, durante a querela da investidura, após vencer uma guerra, a Igreja Católica consegue afirmar-se como o principal poder Terreno para os novos tempos.

A Igreja, ao consolidar-se como Poder Temporal, reestrutura-se, instituindo Séc. XI e XII , fazendo uma verdadeira revolução na organização política e social da Idade Média, adotando a institucionalizadas da- penitência e da confissão: o representante da Igreja passa a decretar a remissão dos pecados no confessionários declarando Ego absolvo te. Surgem as autoridades jurídicas eclesiásticas e retornam os juristas profissionais, o papa Gregório VI institui a supremacia política e legal do papado sobre toda igreja e estabelece a perseguição aos padres casados.

Acompanhando estas mudanças, e o incremento na elaboração do pensamento, surgem as primeiras universidades no Século XIII, e a filosofia Escolástica procura respostas mais acuradas para justificar a autoridade da Igreja Cristã, o que resulta na reivindicação de uma fé que encontra um fundamento racional para sua autoridade, cujo maior representa é Santo Tomás de Aquino que, a partir das categorias da Metafísica Aristotélicas, passa a apresentar a justificativa racional para a fé, inclusive para a existência de Deus.

Em Santo Tomás de Aquino, o Direito passa a encontrar, também, um fundamento racional subordinado à fé e construído através de três categorias: 1) Lex aeterna, a razão divina, que governa o mundo, não cognoscível pelo homem; 2) Lex naturalis, lei divina que pode ser conhecida diretamente pelo homem por meio da razão, já que se trata de uma Grandeza Objetiva que pode ser alcançada pelo homem dotado de razão, conferida por Deus, que o fez a sua imagem e semelhança; 3) Lex Humana, que se manifesta através de aplicações particulares da lei natural: por silogismo ou por especificação.

Na Idade Média, o Direito Positivo tem fundamento no Direito Natural Divino. Na Idade Moderna, o Direito Natural passa a ser laico, mas é a partir das categorias filosóficas da Idade Média, que resultaram do encontro entre a filosofia grega, o direito romano e a religião cristã, que a modernidade vai construir-se. 


\section{Conclusão}

A filosofia grega e o direito romano sofreram um longo período de descontinuidade e ruptura e parte das idéias construídas durante a Idade Antiga perdeu-se. Com o desenvolvimento do cristianismo, das universidades, das escolas de direito e da Igreja Católica no medievo, foi possível reconstruir um novo mundo partindo de idéias que se encontravam esquecidas ou negligenciadas, o que tornou possível o advento da modernidade.

A construção deste novo mundo, porém, é o resultado das escolhas feitas na história a partir de idéias que precisaram ser cultivadas para se manterem vivas e transformadas para se adequarem a nova realidade. Sem elas, porém, o caminho teria sido muito mais longo e difícil. Remontar à antiguidade e ao medievo e valorizar estas idéias significa manter viva a tradição que permitiu a construção dos direitos humanos em sua história efeitual.

Afinal, agora somos responsáveis por escolher o que deverá ser cultivado e mantido e o que deve ser excluído ou rejeitado. Estas decisões são muito mais difíceis do que parecem e a compreensão do desenvolvimento do direito na idade antiga e no medievo pode ajudar a compreender melhor a radical transformação que o surgimento dos direitos humanos ocasionou na sociedade e no Estado lançando luzes sobre o caminho a ser perseguido aqui e agora.

\section{REFERÊNCIAS}

ARISTÓTELES. A Política. 2. ed. Trad. Roberto Leal Ferreira. São Paulo: Martins Fontes, 1998.

BERMAN, Harold J. La formación de la tradición jurídica de Occidente. Trad. Mônica Utrillla de Neira. México: Fondo de Cultura Econômica, 1996.

BOBBIO, Norberto. A Era dos Direitos. Trad. Carlos Nelson Coutinho. Rio de Janeiro: Campus, 1992.

COMPARATO, Fábio Konder. A afirmação Histórica dos Direitos humanos. 3. ed. São Paulo: Saraiva, 2004.

DUMONT, Louis. Homos Hierarchicus. O sistema de castas e suas implicações. 2. ed. Trad. Carlos Alberto da Fonseca. São Paulo: Edusp, 1997.

FERRY, Luc. Aprendendo a viver. Filosofia para os novos tempos. Trad. Vera Lucia dos Reis. Rio de Janeiro: Objetiva, 2007.

GADAMER, Hans-Georg. Verdade e Método: Traços fundamentais de uma hermenêutica filosófica. Trad. Flávio Paulo Meurer. 4. ed. Petrópolis: Vozes, 2002. 
GORDON, Scott. Controlling the State: Constitutionalism from Ancient Athens to Today. Cambridge, Massachusetts and London: Harvard University, 2002.

JACKSON, Vicki C. \& TUSHNET, Mark. Comparative Constitutional Law. 2. ed. New York: Foundation Press and Thomson West, 2006.

JUDT, Tony. Pós-Guerra: uma história da Europa desde 1945. Trad. José Roberto O'Shea. Rio de Janeiro: Objetiva, 2008.

MARÍAS, Julián. História da Filosofia. Trad.. São Paulo: Martins Fontes, 2006.

NEMO, Philippe. Histoire des idées politiques aux temps modernes et contemporains. Paris: PUF, 2002.

NEVES, Marcelo. Entre Têmis e Leviatã: uma relação difícil. São Paulo: Martins Fontes, 2006.

PINTO, Cristiano Paixão de Araújo. Modernidade, tempo e direito. Belo Horizonte: Del Rey, 2002.

SAINT AUGUSTINE. The Confessions. Chicago: Encyclopaedia Britannica, 2007. TRINDADE, Antônio Augusto Cançado. O Direito internacional em um mundo em transformação (Ensaios, 1976-2001). Rio de Janeiro e São Paulo: Renovar, 2002.

. Tratado de Direito Internacional dos Direitos Humanos. 1. ed. Porto Alegre: Sergio Antonio Fabris, 1999. vol. 2.

WARAT, Luis Alberto. Introdução geral ao direito III. O direito não estudado pela teoria jurídica moderna. Porto Alegre: Sérgio Antonio Fabris, 1997.

WIEACKER, Franz. História do Direito Privado Moderno. 3. ed. Trad. A. M. Botelho Hespanha. Lisboa: Fundação Calouste Gulbenkian, 2004.

FROM HUMAN RIGHTS TO FUNDAMENTAL RIGHTS: MODERN LAWBASIS IN ANCIENT AND MEDIEVAL TIMES

Abstract: Human rights are part of citizen's everyday life in contemporary democracies, but they have a very long history. The understanding of human rights history is very important to understand its meaning in modern state and society. The study of ancient and medieval origins of human rights is usually neglected but the actual meaning of human rights in modern society only acquired its importance based upon the Greek philosophy, roman law and Christianity which allowed human rights theory and practice to be built in modern society.

Keywords: Law history. Human rights. Antiquity and medieval. 